
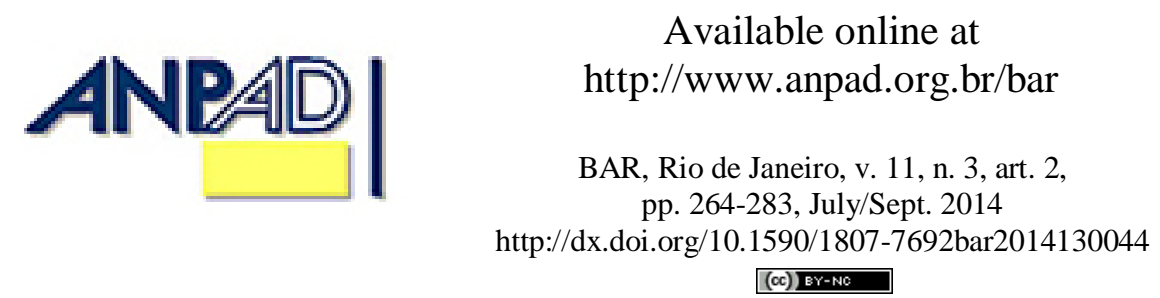

\title{
Hockey Stick Phenomenon: Supply Chain Management Challenge in Brazil
}

Lars Meyer Sanches

E-mail address: larsms@insper.edu.br Insper Instituto de Ensino e Pesquisa Insper, Rua Quatá, 300, 04546-042, São Paulo, SP, Brazil.

Orlando Fontes Lima Jr. E-mail address: oflimaj@ fec.unicamp.br Universidade Estadual de Campinas - LALT/FEC/UNICAMP UNICAMP, Rua Albert Einstein, 951, Sala 02, 13083-852, Campinas, SP, Brazil.

Received 8 November 2013; received in revised form $1^{\text {st }}$ April 2014; accepted 23 April 2014; published online $1^{\text {st }}$ July 2014.

Editor's note. Kleber Fossati Figueiredo served as Action Editor for this article. 


\begin{abstract}
The objective of this study is to investigate a phenomenon that occurs in Brazil, specifically the spike in demand at the end of the sales period, known as the hockey stick phenomenon. This analysis will encompass the causes as well as the impacts of this phenomenon, in a way that allows alternative policies to be evaluated. Data was collected from a Brazilian branch of a large multinational in the non-durable consumer goods industry and in semi-structured interviews conducted face-to-face with executives of 26 clients. The data was used to generate a continuous simulation model based on the methods of systems dynamics. The findings showed that the phenomenon negatively impacted the manufacturer's financial performance in the long term and indicated required changes necessary to remediate the phenomenon. This is an empirical study on the hockey stick phenomenon, a problem that affects diverse companies in Brazil. The study showed that companies should not assume the hockey stick phenomenon to be an exogenous problem; it showed that there are policies able to improve financial performance; and it provided ideas regarding ways to carry out the change process.
\end{abstract}

Key words: hockey stick phenomenon; Brazil; system dynamics; bullwhip effect. 


\section{Introduction}

Companies must consider particular characteristics if they wish to be successful in their ventures in emerging markets (Lorentz, Wong, \& Hilmola, 2007). The hockey stick sales or hockey stick phenomenon, a sales spike at the end of the sales period, is an important characteristics of many markets in Brazil but not exclusive to this country. There are references in the literature to companies in highly diverse industries and countries suffering from the effects of the hockey stick phenomenon (Bradley \& Arntzen, 1999; Chen, 2000; Hines, Holweg, \& Sullivan, 2000; Hoole, 2005; Lee, Padmanabhan, \& Whang, 1997a; Neale \& Willems, 2009; Nyaga, Closs, Rodrigues, \& Calantone, 2007; Oyer, 1998; Shaw, 1996; Singer, Donoso, \& Konstantinidis, 2009; Slone, Mentzer, \& Dittmann, 2007; Sohoni, Bassamboo, Chopra, Mohan, \& Sendil, 2010; Stank, Dittmann, \& Autry, 2011; Sterman, 2006; Umble \& Srikanth, 1990; Villegas \& Smith, 2006; Zotteri, 2013).

As a research topic, the sales spike at the end of the sales period is still under-investigated in the literature (Singer et al., 2009). Agency theory (Chen, 2000), non-cooperative game theory (Singer et al., 2009) and dynamic stochastic (Sohoni et al., 2010) theoretical models have been employed to study this phenomenon. One of our goals is to evaluate the adequacy, with an empirical study, of the policies proposed by previous authors to eliminate the hockey stick phenomenon and also to test new alternatives. Our study expands the scope of previous work and considers, in addition to competition between retailers, the actions and reactions of competing suppliers and consumers, and quantifies the impacts the hockey stick phenomenon has on involved agents' financial performance.

The objective of this study will not be limited to evaluating alternative policies to eliminate the spike in demand at the end of a sales period. This analysis will encompass the causes as well as the impacts of the hockey stick phenomenon. The system dynamics method (Forrester, 1961; Sterman, 2000 ) is used for the study.

\section{Background}

The vast literature regarding changes in the demand along the supply chain is an important source for this research. Jay Forrester's research using difference equation modeling (Forrester, 1961) demonstrated what he called the demand amplification. According to Potter and Lalwani (2008, p. 835) "demand amplification refers to the increase in variability of orders across an echelon within a supply chain". The bullwhip effect was coined by Procter and Gamble executives to describe the problems that they were facing in the diapers market (Lee, Padmanabhan, \& Whang, 1997b). The work of Lee, Padmanabhan and Whang (1997b) was responsible for disseminating this new term. According to Lee et al. (1997b, p. 546) "the bullwhip effect or whiplash effect refers to the phenomenon where orders to the supplier tend to have larger variance than sales to the buyer (i.e., demand distortion), and the distortion propagates upstream in an amplified form (i.e., variance amplification)". Some authors point that demand amplification and bullwhip effect referred to the same phenomenon (D. H. Taylor, 1999; Towill, Zhou, \& Disney, 2007) but according with Lee et al. (1997b) their work differs from Forrester (1961) regarding members' behavior. According to Lee et al. (1997b, p. 548) changes in demand is "an outcome of the strategic interactions among rational supply chain members". Demand amplification, also known as Forrester Effect (Disney \& Towill, 2003), is related demand signal processing and non-zero lead times (Forrester, 1961).

Excessive inventory, inadequate distribution and production capacity, low product availability and high transportation costs are some of the impacts of the bullwhip effect (Lee et al., 1997b). Potter and Lalwani (2008) use a simulation model to quantify the impacts demand amplification has on transportation costs. They stated that demand amplification will affect transport costs due to premium transport rates and inefficient scheduling. Towill and McCullen (1999) report impacts in inventory turns and customer service level as well. 
Many causes for the amplification of demand variability along the supply chain have been pointed out: information and physical delays (Forrester, 1961); agents' irrational behavior (Sterman, 1989); demand forecast updating, order batching, price variations and rationing gaming (Lee et al., 1997b). Paik and Bagchi (2007) used a computer simulation model to suggest that among many of the causes for the bullwhip effect the most significant ones are demand forecasting updating, echelon levels and price variations.

Lee et al. (1997b) mentioned the hockey stick phenomenon and they attribute this phenomenon to order batching. They pointed out that in the case that when customers are assembly plants, the end of the month peak is due to the habit of monthly production planning cycle runs. According to Lee $e t$ al. (1997b) retailers' order batching is related to gain economies in pricing (i.e., volume discounts), transportation, periodic review of ordering processes and transaction costs of processing purchase orders. Lee et al. (1997b) propose a serious of actions to mitigate the effects of order batching: sellthough and inventory data collaboration; reduce transaction costs through electronic data interchange (EDI), less-than-truck-load (LTL) and coordination of delivery schedules. We refer to Bhattacharya and Bandyopadhyay (2011) for a comprehensive review of bullwhip effect literature and order batching in particular.

Lee et al. (1997b, p. 554) also cited that another source of positive order correlation was that "salespeople tend to rush and close deals towards the end of the quarter to meet their quarterly sales target". They demonstrated that when rational behavior agents are submitted to high-low prices policies the bullwhip effect is generated. Lee, Padmanabhan and Whang (1997a) mentioned the impacts of forward buying, a practice where products are purchased prior to the actual demand, on the bullwhip. Forward buying was due to manufacturers' price and quantity discounts that resulted in price fluctuations. They also refer to push ordering when orders are pushed to customers due to salespeople incentives. Ozelkan and Cakanyildirim (2009) coined the term reverse bullwhip effect in pricing (RBP) to the impact of upstream supply chain price changes into retail prices. In order to reduce price fluctuations Lee et al. (1997b) propose the use of Every Day Low Price (EDLP) strategies along with Vendor Management Inventory (VMI) arrangements.

According to Lorentz, Wong and Hilmola (2007) actions to reduce the bullwhip effect are difficult to implement in emerging markets. Handfield and Withers (1993) point out that emerging market executives have gaps in management competencies. Boubekri (2001) proposes that the implementation of supply chain management concepts depends upon market characteristics. Foreign companies can either try to apply their home country supplier-customer relationships policies in emerging markets or adapt them to market environments (Canning \& Hanmer-Lloyd, 2002). Studying the environment in East Europe, Lorentz et al. (2007) points out that general economic development and diverse environmental variables play important roles in setting the structure of the distribution systems and play a crucial role in determining the level of demand amplification. Moori, Perera, and Mangini (2011) concluded that price changes and replenishment policies are the main variables that caused the bullwhip effect in a study conducted in the food supply chain in Brazil. They claim that price changes are due to the habit of end customers searching for promotional prices at retailers. These results can help explain the problems that Wal-Mart had while trying to introduce its EDLP policy in Brazil (Rocha \& Dib, 2002). Wal-Mart tried to apply their home country policies but struggled with the impacts of this decision.

The hockey stick sales phenomenon is also associated with other effects in accounting and economics literature, such as the end of fiscal year effect, channel stuffing, sales manipulation and forward selling (Cohen, Dey, \& Lys, 2008). Forward selling is marked by an attempt by sales personnel to anticipate future requests to reach sales period quotas (Dodd \& Favaro, 2006). Authors of the marketing channels school have associated forward selling and forward buying as a result of the use of temporary discounts (Desai, Koenigsberg, \& Purohit, 2010). Many retailers manage discounts as a profit center that results in forward buying being very important to financial results (Blattberg, Briesch, \& Fox, 1995). According to Buzzell, Quelch and Salmon (1990) the use of EDLPP (every day low purchase price) models similar to that practiced by Wal-Mart allows reducing the negative effects of the fluctuation in demand. Poddar and Donthu (2013) propose a virtual forwarding strategy 
where the goods are pre-paid and delivered to the retailers in later periods. Anily and Hassin (2013) shows that customers respond to high and low price strategies by forward buying products during discount periods. Su and Geunes (2012) demonstrate that in some cases increased revenues generated by trade promotions may be offset by the increase in operation costs.

Umble and Srikanth (1990) mention that the hockey-stick effect occurs in different industries and that the main factor that influences its shape is the length of the reporting period. Bradley and Arntzen (1999) examined hockey stick sales occurring in an electronics company. The authors developed an optimization algorithm in order to define, based on the demand peak at the end of the quarter, the optimum combination of productive capacity and stocks (Bradley \& Arntzen, 1999). Chen (2000) applied agency theory to construct a dynamic theoretical model in which a company that had no competition sold its products through a single sales force without providing discounts. The author proposed changes in the length of the period over which sales remuneration is calculated to ensure a lower demand (Chen, 2000).

Hines, Holweg and Sullivan (2000) mentions that hockey-stick syndrome causes changes in stock levels. They state "the 'hockey-stick' syndrome refers to the fact that sales or production levels generally peak towards the end of a measurement period in order to comply with given performance targets" (Hines et al., 2000, p. 829). They advocate a redesign of sales force and dealer bonuses.

Nyaga, Closs, Rodrigues and Calantone (2007) study the effects of hockey-stick sales, what he calls demand skew, in a configure-to-order environment (CTO) by using a simulation model. They argue that in a CTO environment the policies proposed by Bradley and Arntzen (1999) are not feasible because inventory build-up is not a possibility. They showed that high demand skew negatively impacts customer service. They mention that hockey stick sales is still a common phenomenon in the contemporary business environment and suggest changes in configuration capacity as well as in sales discount procedures and sales incentive models.

Along similar lines, Sohoni, Bassamboo, Chopra, Mohan and Sendil (2010) created a conceptual model to study the impact of incentives in the area of supplier sales on the sales spike. In order to eliminate the sales spike, the sales quota was required to perfectly mimic market demand (Sohoni et al., 2010). Utilizing non-cooperative game theory, Singer et al. (2009) constructed a theoretical model that indicated the fact that retailers use knowledge of future demand and stocks to force suppliers to give discounts to reach sales target is the primary cause for end of month sales spike (Singer et al., 2009). They propose an increase in retailer inventory-holding costs as a way of eliminating the sales spike.

Zotteri (2013) study the skin and personal care sector in Italy and concluded that price fluctuations and forward buys are the major causes for the bullwhip effect. Zotteri (2013) identify that demand peaks tend to occur toward the end of the month, which shows that the hockey stick phenomenon is happening. Zotteri points out that the hockey stick phenomenon was due to sales pushes towards the end of the month as a way to reach monthly sales targets. It is mentioned that monthly targets are not exclusive to salespersons but spread to the entire company. Zotteri (2013) also shows that retailer incentives to reduce inventory holding cost make retailers less willing to forward buy products with high final consumer demand variability and that therefore the bullwhip effect is smaller in those kinds of products. Therefore incentives play a major role in the bullwhip effect. As incentives are defined by company executives, the conclusion is that the bullwhip effect appears to be at least partially self-induced. Zotteri (2013) highlights that the hockey stick did not reduce the service level provided by the manufacturer because these peaks are predictable and therefore the entire operation is prepared to deal with it. Although it generates cost increases caused by excess capacity of supply chain resources (warehouses, warehouses' employees and trucks), Zotteri questions why, if the hockey stick phenomenon negatively impacts companies' costs and the major cause is incentives, executives do not change the incentives? Zotteri (2013) questions if are there trade-offs when eliminating the bullwhip-effect and what would be the barriers to change? 
As can be seen in the bullwhip effect literature, price fluctuation is one of the major causes associated with the phenomenon and therefore a way to reduce its impacts on manufacturers' financial results would be to change price policies to schemes such as EDLP. On the other hand marketing channel studies show that customer dynamic behavior must be considered and that trade promotions can be beneficial for retailers. Su and Geunes (2012) claims that studies must consider supply and demand-side effects, as well as supplier and retailer policy interaction. Disney and Towill (2003) concludes that the effect of changes in pricing and replenishment policies must consider a supply chain perspective as well as a marketing perspective. Zotteri (2013) underscore the role that intraorganization incentives play in price fluctuations and that a change process would demand a lot of effort to be successful. Lee et al. (1997b) stresses actions to reduce the bullwhip effect must be evaluated considering the advantages and disadvantages for both players. Singhal and Singhal (2012) claims that organizations are complex and must be approached as a system and that real-world problems usually involve different areas in the company. Therefore, academic research, to be useful for managers, must also cross discipline boundaries.

\section{Methodology}

\section{Research study approach}

In analyzing the theoretical background, it was concluded that a study on the hockey stick phenomenon needed to take a holistic and dynamic approach. Reactions and delayed effects such as buyer learning and customer forward buying can cause the results of policies to change over time, so suggested policies need to be considered over time. The simulation approach based on the system dynamics method (Forrester, 1961; Sterman, 2000) was adopted so as to be able to deal with problems characterized by dynamic complexity, that is, systems where the actions of a given agent lead to reactions by other agents, also referred to as feedback.

More studies are needed that use explanatory or predictive mathematical models able to solve real problems in the area of operations management (A. Taylor \& Taylor, 2009). System dynamics is an empirical approach that, despite being largely descriptive, also has normative characteristics and adapts to diverse problems in the operations management and supply chain management area (Grobler, Thun, \& Milling, 2008). These characteristics make the method well-suited for this study's objectives to find causes of, impacts from, and alternatives to the hockey stick phenomenon and follow recommendations regarding how to select which approach to take (A. Taylor \& Taylor, 2009).

The methodological steps followed in this study were adapted from Sterman (2000) and Richardson and Pugh (1981), and followed the good practices recommendations for the method (Martinez-Moyano \& Richardson, 2013). The first step was to identify and define the problem. The next phase was to qualitatively evaluate the model. Different data sources were utilized to generate dynamic hypotheses presented in the language of causal loop diagrams representing causality relationships between the different variables involved (Sterman, 2000). The data collected served, jointly with the theoretical framework, as a basis for the next steps, which were the computational model construction (Homer \& Oliva, 2001) and model validation. Ithink software (Ithink, 2006) was used in this step. The simulation model was utilized to identify the causes and evaluate the results of various policies on the performance of the agents involved. These steps were iterative. It was necessary to return to previous steps various times; a good way to portray the method utilized would be a spiral format.

\section{Description of the market and the research site}

The Brazilian non-durable consumer goods industry was chosen for this study because it involves, in addition to a relevant segment of an important Latin American country, a scenario where 
hockey stick sales occurs in an extreme and frequent manner (Yin, 2003). The non-durable consumer goods retail segment in Brazil has a number of peculiarities when compared to developed countries (Rocha \& Dib, 2002). In Brazil, as well as most Latin American countries, expenditures on nondurable consumer goods represent a significant portion of the expenses for a large part of the population. As such, one of the fundamental criteria for choosing the place of purchase is the product price (Oliveira, Freitas, Muniz, \& Prazeres, 2005). Vasconcellos and Sampaio (2009) study results point to a high stockout level in the supermarket sector.

The company that was utilized as the object of this study is the Brazilian subsidiary of a large, multinational food consumer-product manufacturer which will be denoted Consumption Ltd. The company had a diversified, high-quality product line with strong brand recognition, premium prices and distribution throughout the country. A significant part of logistics tasks were performed by a limited number of carriers and logistics service providers. The subsidiary was under pressure from headquarters to improve financial results in Brazil. For more than 20 years the company has been suffering from the hockey stick phenomenon. In 2007, on average $57 \%$ of its monthly sales volume was sold and invoiced in the last 5 days of the period. This spike occurred in all sales channels and regions of the country.

\section{Data collection}

In accordance with the techniques of system dynamics (Morecroft \& Sterman, 1994) the simulation model was constructed from multiple data sources including numeric data, interviews, direct observations and company documents. Data were collected while working with the company over the course of an 18 month period.

The first data source utilized, numeric information, was recorded together with company personnel in order to avoid errors related to interpretation or information accuracy. Among this data were the data utilized to determine the size of the impact of the hockey stick phenomenon on the different logistics elements (see Table 1). For example, to arrive at the value at which the sales spike impacts shipping costs, a model was utilized where scenarios were simulated with different weekly sales percentages. The estimated number of weekly shipments required in each scenario was used to set the rate of asset utilization over the month and the impact that it would have on the carriers' fixed cost structures. Based on the results, a graphic function was generated (Wolstenholme, 1999) that was incorporated into the quantitative computational model.

Data recording was not limited to information collected from the standpoint of a single agent. In order to understand the retailer's point of view, semi-structured interviews were conducted face-toface with purchasing executives of 26 of the company's clients. The questionnaire used was pretested and the data from these interviews were transcribed, consolidated and tabulated. In addition to the quantitative data and written data obtained in the interviews with clients, various in-depth interviews with executives in different areas of the company (Sales, Marketing, Finance and Logistics) were carried out to obtain expert opinions from the different individuals involved in the problem.

\section{Model validation}

The procedures conducted in this stage of the study can be divided into Sargent's (2000) four different types of validity: conceptual model validity, computerized model verification, operational validity and data validity. To increase the confidence that the model adequately represents the system that is being modeled, in other words it has conceptual validity, we conducted the following procedures. First, an executive from Consumption Ltd was trained in the concepts and language of system dynamics and we continuously showed the model to guarantee that it adequately represented the external environment. This executive took part in all meetings with other executives. In the beginning of those meetings the model was showed to the group to see if it correctly represented the data provided in previous meetings. 
The second procedure was to compare the model results with a reference mode to verify that it was able to produce the same behavior pattern (Sterman, 2000). In this case the model results were checked if the model was able to generate the hockey stick sales pattern as in real life. The third procedure was to show the model results to a senior company executive with broad knowledge of the problem and the company as a whole, but who did not participate in the model construction effort. The fourth procedure was to simulate the policies that other companies already tried in real life to solve the hockey stick phenomenon to see if model outputs had the same pattern with those companies' actual results. For instance, another company tried to eliminate the end of the month peak by changing its business calendar to end the sales period in the middle of the month $\left(15^{\text {th }}\right)$. The company sales peak only moved from the end of the month to the middle of the month. We checked if the model outputs were compared with the actual results of those companies to see if the results had the same pattern. Finally, model outputs were also compared with results reported in the literature review, such as the results achieved by Procter and Gamble in the United States (Manning, Bearden, \& Rose, 1998) that implemented a policy that stabilized its prices. As reported by Manning, Bearden and Rose (1998) the model showed that this policy would generate a loss in sales volume.

To verify computerized model adequacy the following tests were conducted: dimensional consistency and partial estimation of the model (Barlas, 1996; Forrester \& Senge, 1980). Dimensional consistency tests were carried by performing software specific functionalities for this test to see if the units used in the model were consistent. Another test was to see if parameters and initial conditions were adequate. A partial estimation procedure (Barlas, 1996) was carried out by isolating sectors of the model and analyzing if results were consistent with what was expected to happen.

Operational validity was tested by conducting extreme condition tests and sensitivity analysis. The goal of the extreme condition test was to check the model output behavior if parameters were set to extreme values. Sensitivity testing followed the same procedure as extreme condition testing but the parameters were submitted to reasonable increases and decreases. The goal was to see if the general model output patterns were still the same even after those changes. After those test the model showed to be robust to parameter changes.

Data validity test were done by continuously reporting the collected data to company personnel in order to avoid errors related to interpretation or information accuracy. The validation process was done continuously, where the confidence of persons regarding the model gradually increased (Barlas, 1996). Parts of the internal validity tests were done in parallel with model construction. Several times it was necessary to reexamine the model and/or collect new data as a result of problems pointed out by the tests. After a series of iterations of the different steps of the process, conducting validity tests as described above did not reject the model and it was possible to make it acceptable to the company managers involved in the process, which qualified it for the next step of simulating the results.

\section{Data analysis}

In order to identify possible causes of the sales spike, a model in dynamic equilibrium was used as the starting point, where parameters were defined so that there would be no sales spike. This scenario simulated the situation of the company before it was impacted by policies or conditions that brought about the sales spike. Starting from this model in equilibrium, relevant variables were individually and jointly (when applicable) altered to determine which ones were able to generate the hockey stick effect. The financial impacts of the sales spike were quantified by comparing the results from the model in equilibrium without the spike with the spiked scenario. To evaluate the adequacy of the policies proposed by previous authors, a scenario with a sales spike was used as a starting point. 


\section{Results and Discussion}

\section{Model structure}

The central structure of the simulation model represents the downstream flow of products within the supply chain (Figure 1). Stocks, represented by rectangles, are cumulative and are mathematically equivalent to integrals (Crescitelli \& Figueiredo, 2009; Sterman, 2000). Stock level depends on inflows and outflows, represented by the arrows. Flows are rates and are mathematically represented by derivatives (Sterman, 2000). In addition to the manufacturer Consumption Ltd, we opted to include within the model's boundaries, consumers' (Households), one manufacturing competitor's (Competitor) and two retailers' (denoted as Main Retailer and Competitor Retailer) activities.

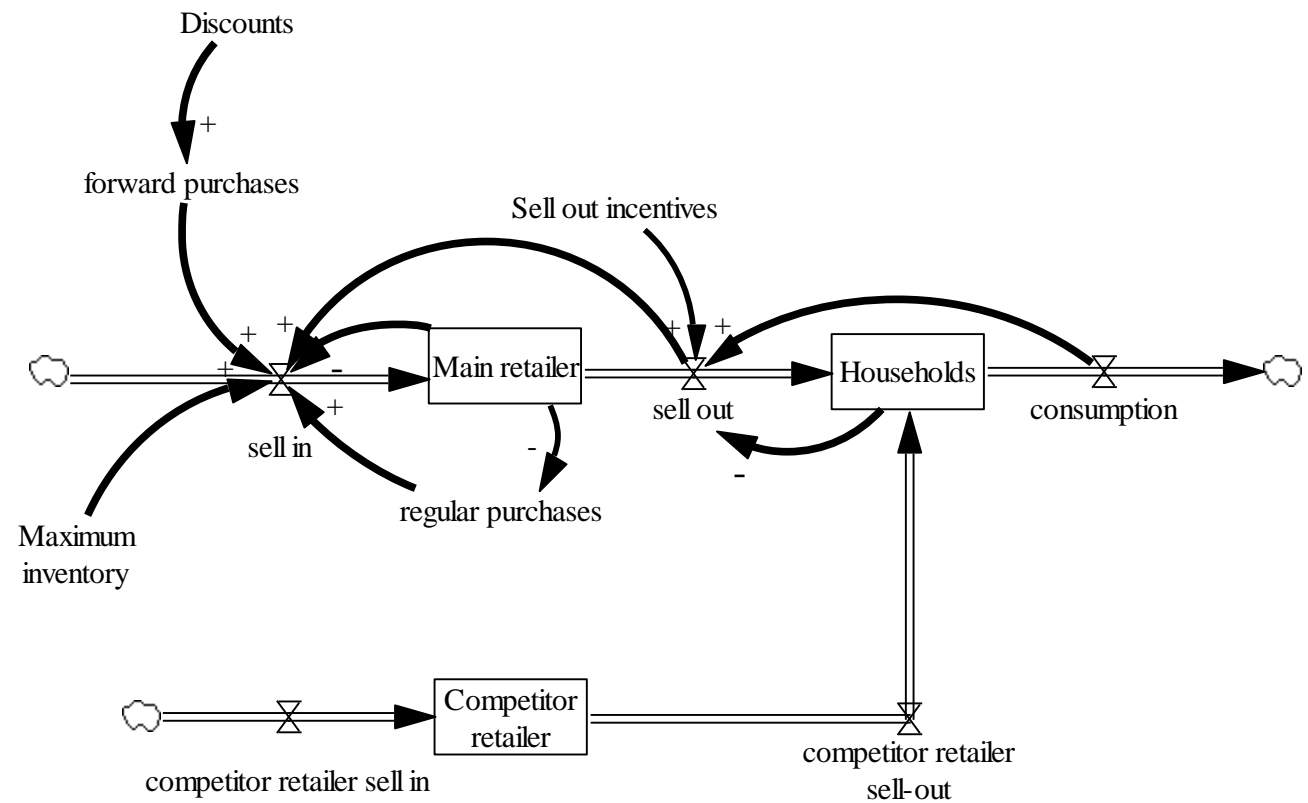

Figure 1. Representation of the Central Part of the Computational Model.

Main Retailer stock of Consumption Ltd products increases directly with sales by the manufacturer to it (sell-in) and falls with its sales to consumers (sell-out).

$$
\operatorname{Main} \text { Retailer }(t)=\int_{t_{0}}^{t}[\text { sell in }- \text { sell out }] d s+\text { Main Retailer }\left(t_{0)}\right.
$$

Similarly to Lee et al. (1997b) we used in our simulation model an order-up-to-S inventory replenishment policy for the retailer where the maximum inventory level (S) varies during low-price (SL) and regular price periods (SH). Manufacturer sell-in occurs only if retailer inventory is below the maximum quantity of products that can be stored (SL). Regular purchases are made to replenish the inventory to the desired level ( $\mathrm{SH}$ ) and forward purchases vary according the discount offered. The simulation model incorporated the literature findings that when there are price fluctuations retailers opt to buy larger quantities at lower prices (Blattberg et al., 1995). In this case maximum inventory level during low-price (SL) is larger than maximum inventory at regular price periods (SH), generating forward purchases.

Household stocks can also be fed by purchases made from the competing retailer (Competitor) and sell-out flow depends on the price discounts offered by retailers to consumers, following the findings in the literature review (Anily \& Hassin, 2013). Household stocks fall with the effective 
consumption of products. The solid arrows capture the influence of variables on flows. The polarity sign to the side of the solid arrow indicates whether the causality relationship is directly (+) or inversely (-) proportional (Crescitelli \& Figueiredo, 2009; Sterman, 2000). The sell-in flow is influenced by the amount of the retailer's stock and by the flow of sales to consumers (sell-out). In addition, it depends on the maximum amount of stock that the retailer is willing to maintain.

\section{Causes of the spike}

According to the retailers interviewed: "At the beginning of the month the supplier charges full prices. At the end of the month he gives discounts to meet targets". The difference between the desired and actual profits for the manufacturer Consumption Ltd causes sellers to forward sell (Dodd \& Favaro, 2006) offering discounts near the end of the month to reach targets (Figure 2). The Main Retailer buyer, whose incentive was to reduce purchasing price, accepted the proposal and bought at a volume much higher than needed (Desai et al., 2010). Like the sales volume, at the beginning there was rapid growth, revenues were increasing making the actual profit reach the target generating the feedback represented by the balancing feedback loop Reach the target (Figure 2). At the beginning of the next month there was no need for the retailer to replace stock (Singer et al., 2009), which again created a need to offer discounts. With the passage of time, Main Retailer's buyer was learning that waiting until the end of the month to make his purchases would be a more favorable business situation. In the comments of one retailer interviewed: "End of month syndrome: suppliers make inviting offers to reach targets. The system receives feedback from speculators (retailer buyers) who follow purchases watching out for offers".

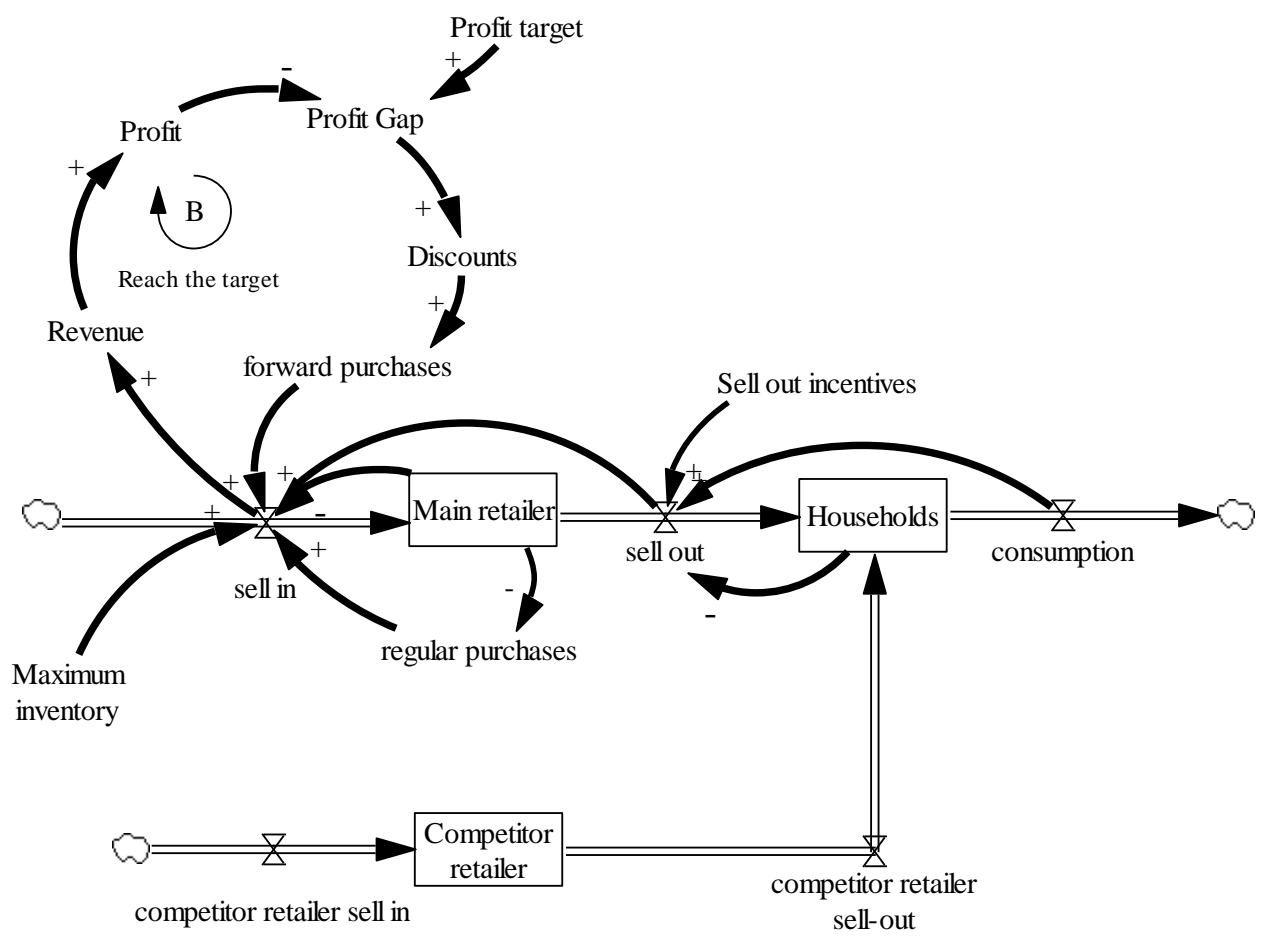

Figure 2. Reach the Target Balancing Loop. 


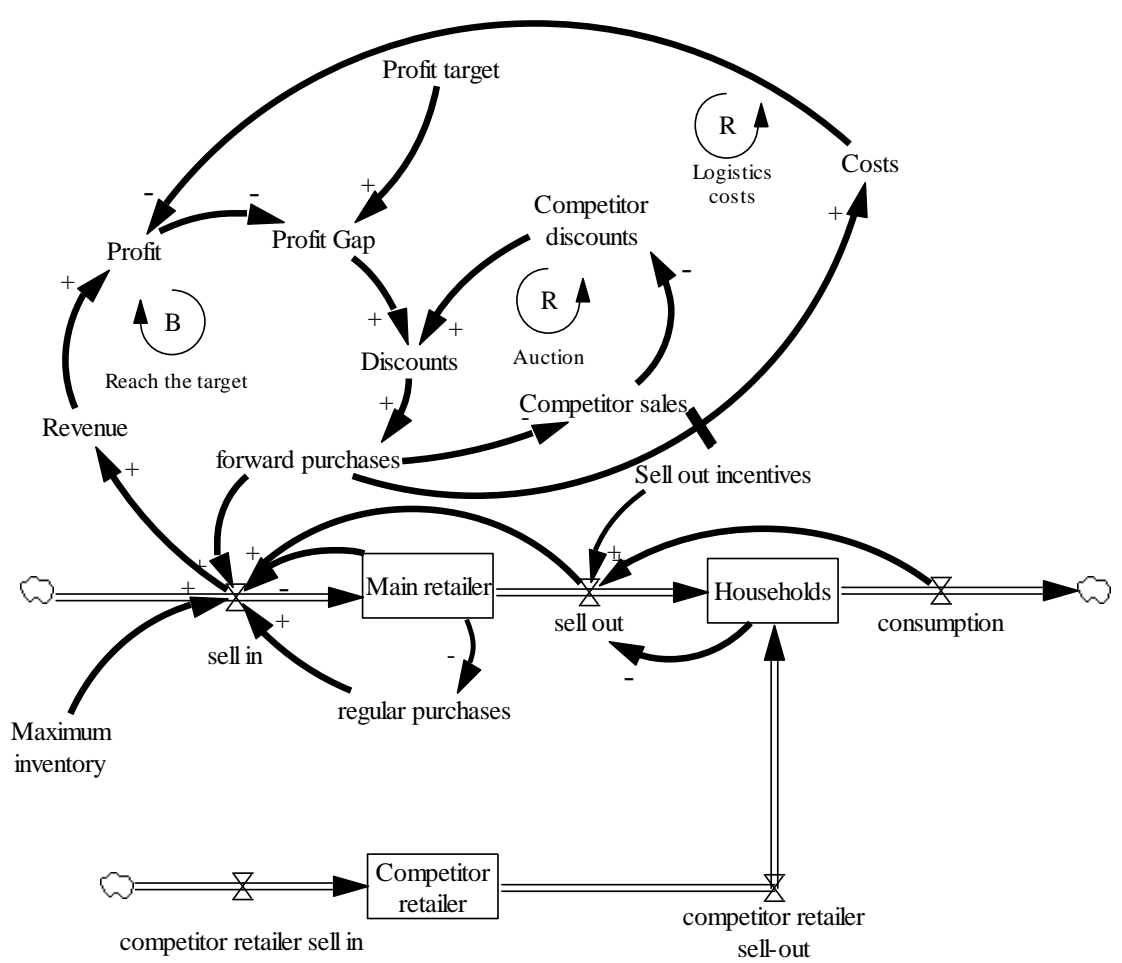

Figure 3. Side Effects of Discounts.

In the same way that the manufacturer Consumption Ltd needed to reach its sales volume, the manufacturer Competitor's seller was also required to reach sales targets and offered discounts whenever the purchasing volume of retailers fell. The retailer's buyer initiated a price war in the last days of month represent as the Auction reinforcing loop (Figure 3). This practice obliged Consumption Ltd to further increase the discounts offered if it wanted to reach the sales volume needed, and thereby the sales spike was perpetuated. The model started on equilibrium with flat sales (25\% in the last week) and quickly generated the hockey stick sales (65\% sales in the last week). The results of the model showed that the hockey stick phenomenon is caused by a mix of three factors: unrealistic profit targets, as well as manufacturer and retailer incentive systems.

\section{Impacts of the spike}

The end of the month sales peak has a number of impacts on the manufacturer's logistics area (see Table 1). This impact was not immediate (or at least it was not immediately recognized), there being a delay (represented by the crossed lines in the middle of the arrow) between the sales spike increase and the increase in logistics costs. The positive feedback loop Logistics Costs in Figure 3 shows that the increase in logistics costs ended up being reflected in the company's actual profit, forcing it to increase sales volume to cover the fall in profit margin. The increase in desired sales volume reinforced the need for more discounts at the end of the month. 
Table 1

\section{Hockey Stick Sales Financial Impacts}

\begin{tabular}{lc}
\hline \multicolumn{1}{c}{ Area } & Impact \\
\hline Transportation & $+18 \%$ \\
Warehousing \& Handling & $+23 \%$ \\
Returns \& Demurrage & $+30 \%$ \\
Finished Goods Inventory & $+12 \%$ \\
Overtime & $+60 \%$ \\
Service level (availability) & $-17 \%$ \\
\hline
\end{tabular}

Note. Source: research results.

Percentage change comparing weekly linear sales versus current sales phasing.

The sales volume at the end of the month, in addition to causing an increase in costs, causes an increase in the variability in demand, which ends up disrupting the availability of products on retailers' shelves (see Table 1). The shortage of products, in turn, makes sell-out flow fall and the retailer buyer reduce the amount purchased. The reduction in the amount bought once again causes Consumption Ltd to increase the amount of discounts. Another effect of increased funds allocated to discounts is a reduction in funds for the marketing and product development departments, reducing the sell-out. For the industry, the long-term result was a fall in profits for the company caused by the increased costs. The loss of profitability is explained by the fact that in the mid and long term, invoicing was not affected. However, as can be seen in Figure 4, in the short term, the volume of sales as well as invoicing rose, showing adaptation to the policy of giving discounts. Clients initially were willing to increase their buying volume motivated by the discounts. When the level of stock reached a maximum plateau, the retailers went on to equivalently buy what was sold to consumers (sell-out).

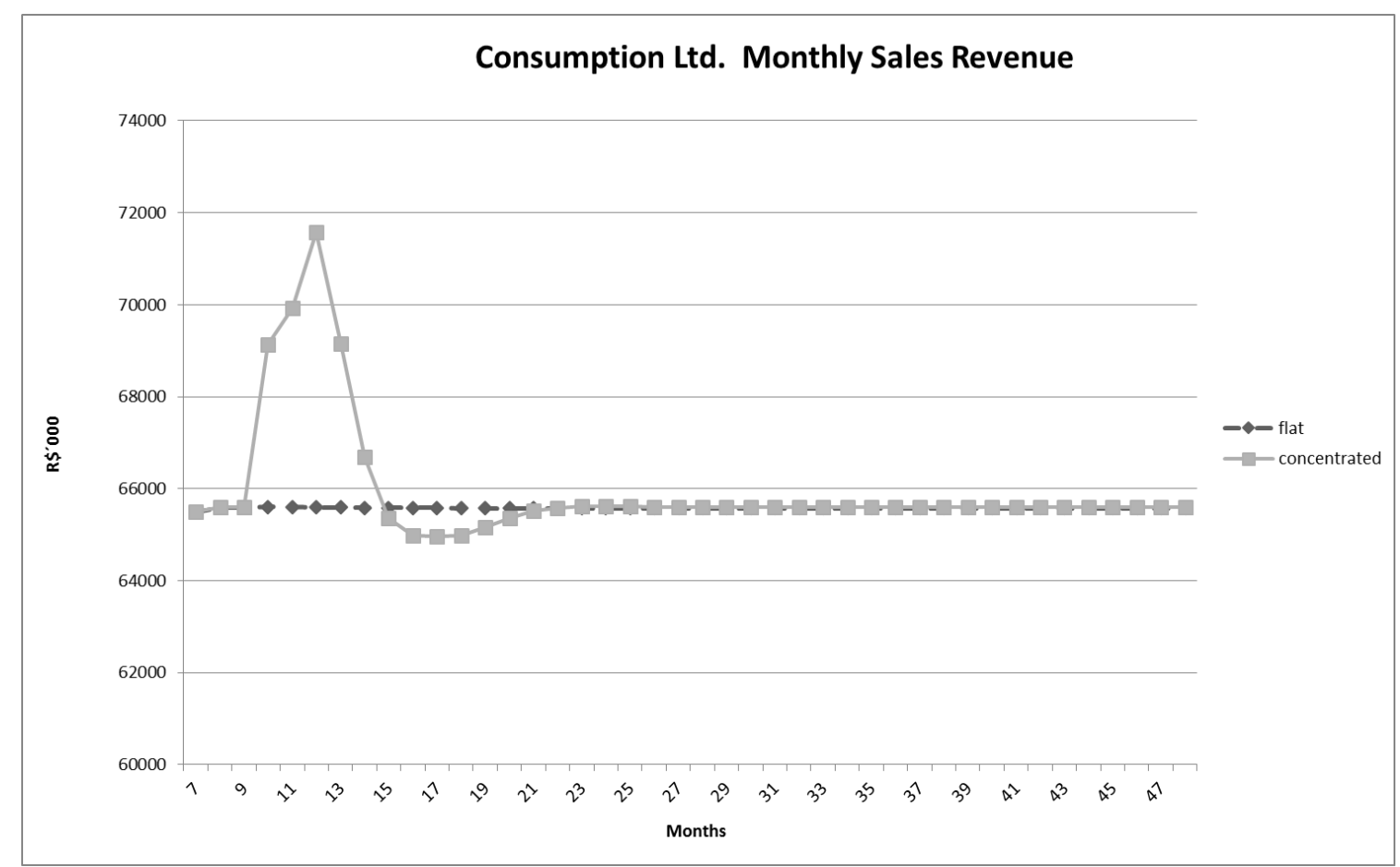

Figure 4. Invoicing by Consumption Ltd over Time. 
Main Retailer's profit was not changed, but its invoicing and sales volume increased. From the cost viewpoint, it resulted in a significant increase in discounts obtained, making the purchasing cost of the products fall. But the drop in the value of purchases was cancelled out by the increased logistics costs. Other impacts were the fall in availability of products on store shelves and the increase in capital tied up in inventory.

\section{Alternative policies}

Three sources were utilized to identify alternative policies to cope with the hockey stick phenomenon: ideas proposed by the theoretical framework (Bradley \& Arntzen, 1999; Buzzell, Quelch, \& Salmon, 1990; Chen, 2000; Poddar \& Donthu, 2013; Sohoni et al., 2010), ideas suggested by Consumption Ltd executives and scenarios that arose while the study was being carried out. In all, nine different policies were found that were able to eliminate invoicing spikes at the end of the month (see Table 2). In addition to these policies, the results from the policy that was currently being employed by Consumption Ltd, which was to increase logistics flexibility, were also analyzed.

Table 2

Policies Able to Eliminate the Hockey Stick Phenomenon

Policy

Constant maximum discount

Logistic discount

Negotiate at the end of the month and make scheduled deliveries the following month

Different closing dates for customers/regions

Change the way of remunerating salesmen

Limit maximum stock

Make feasible financial plans

Increase logistics flexibility

Develop feasible financial plans and shift funds to retail store merchandising

\section{Description}

Eliminate discounts for retailers and Suggested by Consumption Ltd redirect funds to marketing efforts discount possible

Give greater discounts at the beginning of the month

Increase the time period for delivering merchandise

Use different business period calendars for each client/region. For some clients the end of the period will occur in the middle of the month

Stop remunerating salesmen for reaching sales targets

Control retail stock and do not sell if a maximum limit has been reached

Set targets feasible with the market and planned sales actions

Eliminate or reduce the impact of the spike on logistics by increasing production capacity and inventories

Set targets that are feasible with the market and planned sales actions, change sales force incentives and allocate a greater part of funds to activities directed toward sell-out executives

Adapted from Buzzell et al. (1990) (2013)

\section{Source}

Adapted from Singer et al. (2009)

Adapted from Poddar and Donthu Suggested by Consumption Ltd executives

Adapted from Chen (2000)

Scenario proposed by the modeling team

Adapted from Sohoni et al. (2010)

Adapted from Bradley and Arntzen (1999)

Scenario proposed by the modeling team

Note. Percentage change comparing weekly linear sales versus current sales phasing. Source: research results. 
The different policies were evaluated in accordance with the objectives of the two principal agents involved in the problem: the manufacturer Consumption Ltd and the Main Retailer. The profits of companies in the different scenarios were converted into current values for comparative purposes. The recommendation of the policy adopted did not just consider the financial result of the agents involved, but also performance relative to other objectives such as, for example, market share and sales volume. The policy recommended, for eliminating the effects of hockey stick sales, was to implement a Sales \& Operations Planning process that would permit the manufacturer to set profit and sales targets that are better aligned with the market. In addition, the manufacture would have to stop conceding additional discounts, and funds not utilized in sales negotiations would have to be directed to in-store practices that would increase retail sales to the final consumer (sell-out). The sales force incentives should also be repositioned to focus on sell-out. Another challenge, perhaps more difficult to overcome, was that even though the policy had a positive impact on Consumption's profit in the medium and long term, in the short term there was a marked fall in the financial result (see Figure 5). The fall occurred, and then with the implementation of the new policy, the retailer's buyer lowered their stock level and consequently continued to buy a quite reduced amount of products for several months. With this policy, retailer profit in the long term would rise mostly because of reduction in costs and inventory levels.

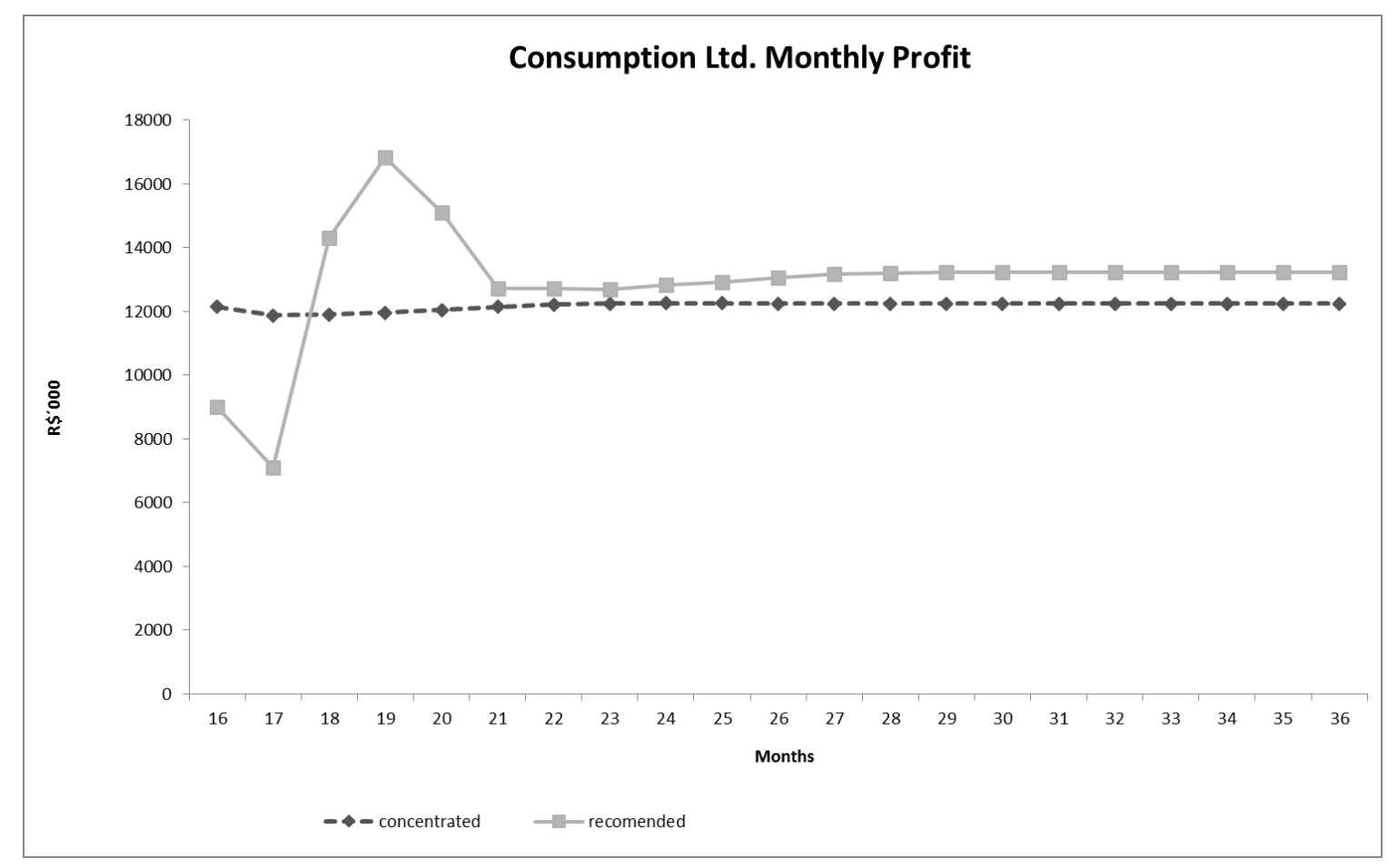

Figure 5. Financial Result of the Proposed Policy over Time.

\section{Managerial Implications}

There was a general view among company executives that the sales spike is a problem caused by exogenous variables and, therefore, could not be eliminated. This study showed that the cause is an endogenous variable. The results of this study can be used to educate executives from other companies that might also believe that the sales spike is caused by exogenous variables and therefore increase their desire to eliminate the hockey stick phenomenon.

The study quantified the impacts of the sales spike on various lines of the company's income statement. It showed that for the manufacturer there is, in the long term, a loss in profitability caused 
by a neutral effect on revenues, combined with increased costs. The amount of assets tied up in the business also increased due to higher inventory levels and fixed assets. The product availability to end consumers also decreases and the amount of investments in brand loyalty and product innovation are also diminished. If you considerer the increased competition in emerging markets, the impacts of the hockey stick phenomenon can be critical for companies' long-term success. This can result in two consequences. For companies that are already affected by hockey stick sales, quantification of the impact can be helpful in convincing upper management of the need to implement alternative policies. For companies that are not affected by a sales spike, this study could serve as an alert, primarily in times of depressed sales. The results of the study also showed that retailers, despite not having their profit margin impacted, are able to increase their sales volume and discounts obtained but increased the amount of capital tied up in inventory. Those results have to be taken into account to see what the barriers to implement changes would be.

According to these results, to eliminate the hockey stick phenomenon companies must make major changes in their organization, especially in the Sales area. The Sales area must change their price discount policies, incentive schemes and change their focus to sell-out activities. It is also necessary to revisit the way company targets are set. On the other hand, the area that would collect the majority of the benefits is Operations \& Logistics. The model also showed that it is necessary to sacrifice profits and sales volume in the short term until retailers lower their stock levels and that retailer buyers would be contrary to this policy because they would not be able to get discounts at the end of the month. This can serve to alert executives of the need to develop a plan for gradual transition, in which the change in policy does not affect all clients at the same time. In addition, it draws attention to the importance of defining the best time for implementing change and draws attention to an obstacle that companies will have to deal with if they want to eliminate the hockey stick phenomenon. The results of this study also help executives anticipate the barriers that they will have to face. Manufacturers' sales departments will offer more resistance, as they have to make most of the changes. In addition, retail buyers will also face change, and thus be resistant. The problems that WalMart (Rocha \& Dib, 2002) experienced while implementing EDLP are an example of how hard it is to actually make those changes with different supply chain players.

We believe that this study satisfies the criteria utilized by executives to evaluate the utility of a research study (de-Margerie \& Jiang, 2011). This study is focused on solving a practical problem; it has proposed a feasible solution to be implemented; it provides insights and helps understand a given phenomenon (de-Margerie \& Jiang, 2011). The results of this study are already being successfully used by companies to eliminate the problem. This model can be adapted by other companies that face the hockey stick phenomenon and can help them challenge imbedded assumptions that could be jeopardizing companies results, quantify its impacts and test policies prior to their actual implementation.

\section{Conclusions and Research Implications}

This study makes a number of contributions toward the development of knowledge in the field. By being an empirical study analyzing hockey stick sales, it answers the calls for more empirical research studies using simulation methods regarding the challenges of operations management in emerging countries (A. Taylor \& Taylor, 2009). By examining the viewpoint of the manufacturer as well as competitors and by considering the problem of inadequate internal integration, the study follows prior suggestions about how to investigate this type of problem (Johnston, Mccutcheon, Stuart, \& Kerwood, 2004).

The results of this study are consistent with Sohoni et al. (2010), indicating demand information asymmetry as a causative factor of the sales spike and does not reject the hypothesis that retailers utilize their product inventories to force the supplier to give a discount to reach the sales target (Singer et al., 2009). It does not reject the findings of the bullwhip literature that price promotions cause 
demand variations (Lee et al., 1997b) and that incentives drive the attempt to forward sell by using temporary price discounts (Desai et al., 2010; Dodd \& Favaro, 2006; Zotteri, 2013). It also aligns with the view that organizations are complex systems and that real-world problems involve different departments (Singhal \& Singhal, 2012).

By quantifying the different impacts on the financial result of the agents involved, this study contributes to studies taking a systems approach to effects of discount policies on companies' marketing and supply chain areas (Lee et al., 1997b; Potter \& Lalwani, 2008; Powers \& Closs, 1987; Towill \& McCullen, 1999; Zotteri, 2013). As in previous studies (Singer et al., 2009), this study showed that one of the effects of the sales spike is increased levels of retail stock. It helped to expand these impacts to other logistics functions such as the increase in product returns. The results do not refute the findings of other studies on the negative effect of promotions on the profitability of the industry in the long term (Blattberg et al., 1995) and that there is an increase in sales volume for retailers (Su \& Geunes, 2012). Contrary with Zotteri (2013) this study shows that manufacturer service level to retailers is reduced. It proposes another side effect that is reduction in funds for the marketing and product development departments.

The policy proposed by this study supports the suggestion to eliminate the sales spike through better agreement between the value of the sales quota and market demand (Sohoni et al., 2010). But in contrast to prior studies, it also indicates a need to reallocate sales efforts to point-of-sale activities. The role of incentives (Cohen et al., 2008) and sales remuneration (Chen, 2000) as causes of forwardbuying proposed in the literature in the area of accounting and economics was confirmed by this study. The impact of temporary discounts on forward-buying and consequently on the hockey stick phenomenon do not reject previous studies (Desai et al., 2010). A contribution of this study is to point out that only a policy that combines changes in different areas of a company (sales, marketing, logistics and human resources) is capable of eliminating the hockey stick phenomenon and generating a positive financial return. It shows that using fixed prices strategies such as EDLP could achieve better results if implemented with other changes in the sales area. This results contributes to the literature that debates the ways that the impact of price discounts in the bullwhip effect can be mitigated (Disney \& Towill, 2003; Lee et al., 1997b; Su \& Geunes, 2012) and the claim for studies that consider effects for all the players of the supply chain (Lee et al., 1997a). It also shows that policies that consider market characteristics such as the ones indicated by Moori et al. (2011) have a better chance of being successfully implemented in emerging markets where there are gaps in management competencies that must be taken into account (Lorentz et al., 2007).

This study follow Zotteri (2013) claim to elucidate the trade-offs to eliminate demand variations and the barriers to implement the changes. It's important to remark that studies must not only show what the optimal solution is, but also show how this proposed policy will affect companies' results in the short and long term. In this way the chance for them to make an impact in companies' decisions would increase (de-Margerie \& Jiang, 2011).

\section{Limitations}

The first of these is the study's scope. Although this study utilized results obtained from qualitative interviews conducted with various retailers, the primary source of data was from the personnel of one specific company. Consequently, it is not statistically valid to generalize the results of this study. Within the company that served as the basis for modeling, the level of participation by persons in different operational areas was not the same. As a result, various kinds of information that might have been collected quantitatively were substituted for by qualitative sources.

\section{Future research directions}

A comparative study between large companies and similar industry sectors in which a group has or does not have invoicing spikes could be an interesting approach to understanding this 
phenomenon's impacts. The combined use of system dynamics and modeling based on discrete simulation may be very useful for refining the quantification of the impact of the spike on logistics costs and the corresponding evaluation of policy results. The use of alternative methodologies could contribute to further test this study's results.

\section{References}

Anily, S., \& Hassin, R. (2013). Pricing, replenishment, and timing of selling in a market with heterogeneous customers. International Journal of Production Economics, 145(2), 672-682. doi: $10.1016 /$ j.ijpe.2013.05.021

Barlas, Y. (1996). Formal aspects of model validity and validation in system dynamics. System Dynamics Review, 12(3), 183-210. doi: 10.1002/(SICI)1099-1727(199623)12:3<183::AIDSDR103>3.0.CO;2-4

Bhattacharya, R., \& Bandyopadhyay, S. (2011). A review of the causes of bullwhip effect in a supply chain. The International Journal of Advanced Manufacturing Technology, 54(9), 12451261. doi: 10.1007/s00170-010-2987-6

Blattberg, R. C., Briesch, R., \& Fox, E. J. (1995). How promotions work. Marketing Science, 14(3), 122-132. doi: 10.1287/mksc.14.3.G122

Boubekri, N. (2001). Technology enablers for supply chain management. Integrated Manufacturing Systems, 12(6), 394-399. doi: 10.1108/EUM0000000006104

Bradley, J. R., \& Arntzen, B. C. (1999). The simultaneous planning of production, capacity, and inventory in seasonal demand environments. Operations Research, 47(6), 795-806. doi: 10.1287/opre.47.6.795

Buzzell, R. D., Quelch, J. A., \& Salmon, W. J. (1990). The costly bargain of trade promotion. Harvard Business Review, 68(2), 141-149.

Canning, L., \& Hanmer-Lloyd, S. (2002). Modelling the adaptation process in interactive business relationships. Journal of Business \& Industrial Marketing, 17(7), 615-636. doi: $10.1108 / 08858620210451127$

Chen, F. (2000). Sales-force incentives and inventory management. Manufacturing \& Service Operations Management, 2(2), 186-202. doi: 10.1287/msom.2.2.186.12351

Cohen, D. A., Dey, A., \& Lys, T. Z. (2008). Real and accrual-based earnings management in the preand post-Sarbanes Oxley periods. The Accounting Review, 83(3), 757-787. doi: 10.2308/accr.2008.83.3.757

Crescitelli, E., \& Figueiredo, J. B. (2009). Brand equity evolution: a system dynamics model. Brazilian Administrative Review, 6(2), 101-117. Retrieved from http://www.scielo.br/pdf/bar/v6n2/v6n2a03.pdf. doi: 0.1590/S1807-76922009000200003

de-Margerie, V., \& Jiang, B. (2011). How relevant is OM research to managerial practice? An empirical study of top executives' perceptions. International Journal of Operations \& Production Management, 31(2), 124-147. doi: 10.1108/01443571111104737

Desai, P. S., Koenigsberg, O., \& Purohit, D. (2010). Forward buying by retailers. Journal of Marketing Research, 47(1), 90-102. doi: 10.1509/jmkr.47.1.90 
Disney, S. M., \& Towill, D. R. (2003). On the bullwhip and inventory variance produced by an ordering policy. Omega, 31(3), 157-167. doi: 10.1016/S0305-0483(03)00028-8

Dodd, D., \& Favaro, K. (2006). Managing the right tension. Harvard Business Review, 84(12), 62-74.

Forrester, J. W. (1961). Industrial dynamics. Waltham, MA: Pegasus Communications.

Forrester, J. W., \& Senge, P. M. (1980). Tests for building confidence in system dynamics models. In A. A. Legasto Jr., J. W. Forrester, \& J. M. Lyneis (Eds.), System dynamics, TIMS Studies in the Management Sciences (pp. 209-228). New York: North-Holland.

Grobler, A., Thun, J.-H., \& Milling, P. M. (2008). System dynamics as a structural theory in operations management. Production and Operations Management, 17(3), 373-384. doi: $10.3401 /$ poms. 1080.0023

Handfield, R., \& Withers, B. (1993). A comparison of logistics management in Hungary, China, Korea and Japan. Journal of Business Logistics, 14(1), 81-109.

Hines, P., Holweg, M., \& Sullivan, J. (2000). Waves, beaches, breakwaters and rip currents - a threedimensional view of supply chain dynamics. International Journal of Physical Distribution \& Logistics Management, 30(10), 827-846. doi: 10.1108/09600030010351219

Homer, J., \& Oliva, R. (2001). Maps and models in system dynamics: a response to Coyle. System Dynamics Review, 17(4), 347-355. doi: : 10.1002/sdr.224

Hoole, R. (2005). Five ways to simplify your supply chain. Supply Chain Management: An International Journal, 10(1), 3-6. doi: 10.1108/13598540510578306

Ithink (2006). (Version 9.0.3) [Software]. Lebanon, NH, USA: Isee Systems.

Johnston, D. A., McCutcheon, D. M., Stuart, F. I., \& Kerwood, H. (2004). Effects of supplier trust on performance of cooperative supplier relationships. Journal of Operations Management, 22(1), 23-38. doi: 10.1016/j.jom.2003.12.001

Lee, H. L., Padmanabhan, V., \& Whang, S. (1997b). Information distortion in supply chain: the bullwhip effect. Management Science, 43(4), 546-558. doi: 10.1287/mnsc.43.4.546

Lee, H. L., Padmanabhan, V., \& Whang, S. (1997a). The bullwhip effect in supply chains. Sloan Management Review, 38(3), 93-102.

Lorentz, H., Wong, C. Y., \& Hilmola, O.-P. (2007). Emerging distribution systems in central and Eastern Europe: Implications from two case studies. International Journal of Physical Distribution \& Logistics Management, 37(8), 670-697. doi: 10.1108/09600030710825702

Manning, K. C., Bearden, W. O., \& Rose, R. L. (1998). Development of a theory of retailer response to manufacturers' everyday low cost programs. Journal of Retailing, 74(1), 107-137. doi: $10.1016 / \mathrm{S} 0022-4359(99) 80090-6$

Martinez-Moyano, I. J., \& Richardson, G. P. (2013). Best practices in system dynamics modeling. System Dynamics Review, 29(2), 102-123. doi: 10.1002/sdr.1495

Moori, R. G., Perera, L. C. J., \& Mangini, E. R. (2011). Uma análise investigativa do efeito chicote na cadeia de suprimentos da indústria alimentícia. Revista de Gestão, 18(3), 469-488. doi: $10.5700 /$ rege 436

Morecroft, J. D. W., \& Sterman, J. D. (Eds.). (1994). Modeling for learning organizations. Portland, OR: Productivity Press. 
Neale, J. J., \& Willems, S. P. (2009). Managing inventory in supply chains with nonstationary demand. Interfaces, 39(5), 388-399. doi: 10.1287/inte.1090.0442

Nyaga, G., Closs, D., Rodrigues, A., \& Calantone, R. (2007). The impact of demand uncertainty and configuration capacity on customer service performance in a configure-to-order environment. Journal of Business Logistics, 28(2), 83-104. doi: 10.1002/j.2158-1592.2007.tb00059.x

Oliveira, S. P., Freitas, F. V., Muniz, L. B., \& Prazeres, R. (2005). Hygienical-sanitary conditions of the food commerce of the city of Ouro Preto, MG. Revista Higiene Alimentar, 19(136), 26-31.

Oyer, P. (1998). Fiscal year ends and nonlinear incentive contracts: the effect on business seasonality. Quarterly Journal of Economics, 113(1), 149-185. doi: 10.1162/003355398555559

Ozelkan, E. C., \& Cakanyildirim, M. (2009). Reverse bullwhip effect in pricing. European Journal of Operational Research, 192(1), 302-312. doi: 10.1016/j.ejor.2007.09.009

Paik, S.-K., \& Bagchi, P. K. (2007). Understanding the causes of the bullwhip effect in a supply chain. International Journal of Retail \& Distribution Management, 35(4), 308-324. doi: $10.1108 / 09590550710736229$

Poddar, A., \& Donthu, N. (2013). Improving trade promotions through virtual forward buying. Journal of Business \& industrial Marketing, 28(1), 16-28. doi: 10.1108/08858621311285688

Potter, A., \& Lalwani, C. (2008). Investigating the impact of demand amplification on freight transport. Transportation Research Part E: Logistics and Transportation Review, 44(5), 835846. doi: $10.1016 /$ j.tre.2007.06.001

Powers, T., \& Closs, D. (1987). An examination of the effects of trade incentives on logistical performance in a consumer products distribution channel. Journal of Business Logistics, 8(2), 1-28.

Richardson, G. P., \& Pugh, A. L. III (1981). Introduction to system dynamics modeling with dynamo. Cambridge, MA: MIT Press.

Rocha, A., \& Dib, L. A. (2002). The entry of Wal-Mart in Brazil and the competitive responses of multinational and domestic firms. International Journal of Retail \& Distribution Management, 30(1), 61-73. doi: 10.1108/09590550210415266

Sargent, R. G. (2000). Verification, validation, and accreditation of simulation models. Proceedings of Winter Simulation Conference 2000, Orlando, FL, 32.

Shaw, R. (1996). Creating a ring of commitment to customers. Journal of Marketing Practice: Applied Marketing Science, 2(3), 71-92. doi: 10.1108/EUM0000000004299

Singer, M., Donoso, P., \& Konstantinidis, G. (2009). Who wants to break the hockey-stick sales pattern in the supply chain? Annals of Operations Research, 169(1), 131-147. doi: 10.1007/s10479-008-0480-5

Singhal, K., \& Singhal, J. (2012). Imperatives of the science of operations and supply-chain management. Journal of Operations Management, 30(3), 237-244. doi: 10.1016/j.jom.2011.11.003

Slone, R. E., Mentzer, J. T., \& Dittmann, J. P. (2007). Are you the weakest link in your company's supply chain? Harvard Business Review, 85(9), 116-127.

Sohoni, M. G., Bassamboo, A., Chopra, S., Mohan, U., \& Sendil, N. (2010). Threshold incentives over multiple periods and the sales hockey stick phenomenon. Naval Research Logistics, 57(6), 503518. doi: 10.1002/nav.20417 
Stank, T. P., Dittmann, J. P., \& Autry, C.W. (2011). The new supply chain agenda: a synopsis and directions for future research. International Journal of Physical Distribution \& Logistics Management, 41(10), 940-955. doi: http://dx.doi.org/10.1108/09600031111185220

Sterman, J. D. (1989). Modeling managerial behavior: misperceptions of feedback in a dynamic decision making experiment. Management Science, 35(3), 321-339. doi: http://dx.doi.org/10.1287/mnsc.35.3.321

Sterman, J. D. (2000). Business dynamics: systems thinking and modeling for a complex world. Boston: Irwin McGraw-Hill.

Sterman, J. D. (2006). Operational and behavioral causes of supply chain instability. In O. A. C. Torres \& F. A. V. Morán (Eds.), The bullwhip effect in supply chains: a review of methods, components and cases (pp. 17-56). Hampshire, England: Palgrave McMillan.

Su, Y., \& Geunes, J. (2012). Price promotions, operations cost, and profit in a two-stage supply chain. Omega, 40(6), 891-905. doi: 10.1016/j.omega.2012.01.010

Taylor, D. H. (1999). Measurement and analysis of demand amplification across the supply chain. International Journal of Logistics Management, 10(2) 55-70. doi: 10.1108/09574099910805996

Taylor, A., \& Taylor, M. (2009). Operations management research: contemporary themes, trends and potential future directions. International Journal of Operations \& Production Management, 29(12), 1316-1340. doi: 10.1108/01443570911006018

Towill, D. R., \& McCullen, P. (1999). The impact of agile manufacturing on supply chain dynamics. The International Journal of Logistics Management, 10(1), 83-96. doi: $10.1108 / 09574099910805879$

Towill, D. R., Zhou, L., \& Disney, S. M. (2007). Reducing the bullwhip effect: looking through the appropriate lens. International Journal of Production Economics, 108(1-2), 444-453. doi: 10.1016/j.ijpe.2006.12.024

Umble, M. M., \& Srikanth, M. L. (1990). Synchronous manufacturing: principles for world class excellence. Cincinnati: South-Western Publishing Company.

Vasconcellos, L. H. R., \& Sampaio, M. (2009). The stockouts study: an examination of the extent and the causes in the São Paulo supermarket sector. Brazilian Administration Review, 6(3), 263-279. Retrieved from http://www.scielo.br/pdf/bar/v6n3/v6n3a07.pdf. doi: 10.1590/S180776922009000300007

Villegas, F. A., \& Smith, N. R. (2006). Supply chain dynamics: analysis of inventory vs. order oscillations trade-off. International Journal of Production Research, 44(6), 1037-1054. doi: $10.1080 / 00207540500338203$

Wolstenholme, E. F. (1999). Qualitative vs. quantitative modelling: the evolving balance. Journal of the Operational Research Society, 50(4), 422-428. doi: 10.1057/palgrave.jors.2600700

Yin, R. K. (2003). Case study research: design and methods (3rd ed.). Thousand Oaks, CA: Sage Publications.

Zotteri, G. (2013). An empirical investigation on causes and effects of the bullwhip-effect: evidence from the personal care sector. International Journal of Production Economics, 143(2), 489-498. doi: 10.1016/j.ijpe.2012.06.006 